\title{
Experience Modulates the Effects of Histone Deacetylase Inhibitors on Gene and Protein Expression in the Hippocampus: Impaired Plasticity in Aging
}

\author{
Angila S. Sewal, ${ }^{1,2}$ Holger Patzke, ${ }^{3}$ Evelyn J. Perez, ${ }^{1}$ Pul Park, ${ }^{1}$-Elin Lehrmann, ${ }^{4}$ Yongqing Zhang, ${ }^{4}$ Kevin G. Becker, ${ }^{4}$ \\ Bonnie R. Fletcher, ${ }^{1}$ Jeffrey M. Long, ${ }^{1}$ and Peter R. Rapp ${ }^{1}$ \\ ${ }^{1}$ Neurocognitive Aging Section, National Institute on Aging, Baltimore, Maryland 21224, ${ }^{2}$ Graduate Program in Neuroscience, Icahn School of Medicine at \\ Mount Sinai, New York, New York 10029, ${ }^{3}$ FORUM Pharmaceuticals, Waltham, Massachusetts 02451, and ${ }^{4}$ Gene Expression and Genomics Unit, National \\ Institute on Aging, Baltimore, Maryland 21224
}

\begin{abstract}
The therapeutic potential of histone deacetylase inhibitor (HDACi) treatment has attracted considerable attention in the emerging area of cognitive neuroepigenetics. The possibility that ongoing cognitive experience importantly regulates the cell biological effects of HDACi administration, however, has not been systematically examined. In an initial experiment addressing this issue, we tested whether water maze training influences the gene expression response to acute systemic HDACi administration in the young adult rat hippocampus. Training powerfully modulated the response to HDACi treatment, increasing the total number of genes regulated to nearly 3000 , including many not typically linked to neural plasticity, compared with $<300$ following HDACi administration alone. Although water maze training itself also regulated nearly 1800 genes, the specific mRNAs, gene networks, and biological pathways involved were largely distinct when the same experience was provided together with HDACi administration. Next, we tested whether the synaptic protein response to HDACi treatment is similarly dependent on recent cognitive experience, and whether this plasticity is altered in aged rats with memory impairment. Whereas synaptic protein labeling in the young hippocampus was selectively increased when HDACi administration was provided in conjunction with water maze training, combined treatment had no effect on synaptic proteins in the aged hippocampus. Our findings indicate that ongoing experience potently regulates the molecular consequences of HDACi treatment and that the interaction of recent cognitive experience with histone acetylation dynamics is disrupted in the aged hippocampus.
\end{abstract}

Key words: cognitive aging; epigenetics; histone acetylation; microarray; synaptic protein

Significance Statement

The possibility that interventions targeting epigenetic regulation could be effective in treating a range of neurodegenerative disorders has attracted considerable interest. Here we demonstrate in the rat hippocampus that ongoing experience powerfully modifies the molecular response to one such intervention, histone deacetylase inhibitor (HDACi) administration. A single learning episode dramatically shifts the gene expression profile induced by acute HDACi treatment, yielding a qualitatively distinct hippocampal transcriptome compared with the influence of behavioral training alone. The downstream synaptic protein response to HDACi administration is similarly experience-dependent, and we report that this plasticity is disrupted in the aged hippocampus. The findings highlight that accommodating the modulatory influence of ongoing experience represents a challenge for therapeutic development in the area of cognitive neuroepigenetics.

\section{Introduction}

Evidence that histone deacetylase inhibitor (HDACi) administration can enhance synaptic plasticity and long-term memory consolidation has prompted considerable interest in the therapeutic

Received Sept. 9, 2014; revised July 6, 2015; accepted July 11, 2015.

Author contributions: A.S.S. and P.R.R. designed research; A.S.S., E.J.P., P.P., E.L., and J.M.L. performed research; H.P., Y.Z., and K.G.B. contributed unpublished reagents/analytic tools; A.S.S., Y.Z., K.G.B., and P.R.R. analyzed data; A.S.S., B.R.F., J.M.L., and P.R.R. wrote the paper. potential of HDACis for a wide array of psychiatric and neurodegenerative disorders (Abel and Zukin, 2008). HDACis are thought to regulate gene transcription in part by prolonging histone acetylation and modifying chromatin structure (Peixoto and Abel, 2013). Al- 
though HDACi administration is known to enhance late-phase long-term potentiation (Alarcón et al., 2004; Levenson et al., 2004; Vecsey et al., 2007), induce synaptic protein expression, and increase dendritic spine density (Fischer et al., 2007; Guan et al., 2009), the influence of ongoing experience on the response to HDACi-induced acetylation is poorly understood. The majority of studies in this area have examined the effects of HDACi treatment provided together with some form of behavioral experience, such as explicit memory testing, or environmental enrichment (Levenson et al., 2004; Fischer et al., 2007; Gräff et al., 2014). Thus, it remains unclear whether HDAC inhibition is the primary driver of the cell biological response observed in previous reports or whether the nature of ongoing experience also plays a critical role. Earlier work has also focused predominantly on plasticity-related markers, and the breadth of potential HDACi effects on other pathways has received less attention. To address these issues, we directly tested whether water maze training dictates the gene expression response to HDACi administration in the principal cell fields of the young adult rat hippocampus.

Our results indicated that recent behavioral experience known to potently engage the hippocampus (Castellano et al., 2012; Fletcher et al., 2006, 2014) powerfully modulates the influence of HDACi treatment on hippocampal mRNA expression, regulating broad constellations of genes in patterns qualitatively distinct from the effect of either HDAC inhibition or behavioral training alone. On the basis of these observations, we also assessed whether the previously reported effects of HDACi treatment on dendritic spine and synaptic proteins (Fischer et al., 2007; Guan et al., 2009; Gräff et al., 2014) are similarly dependent on ongoing experience. Recent reports suggest that altered epigenetic dynamics likely contribute to age-related deficits in synaptic plasticity and memory (Peleg et al., 2010; Penner et al., 2010, 2011; Castellano et al., 2012). Accordingly, in a final experiment, we tested whether the influence of cognitive experience on the synaptic protein response to HDACi administration is disrupted in the hippocampus of aged rats that display memory deficits. Although HDACi administration reliably increased hippocampal histone acetylation independent of recent experience, a synaptic protein response to HDACi treatment in the young adult hippocampus was only observed in animals also provided water maze training. The aged hippocampus, by comparison, failed to display enhanced synaptic labeling under any condition. The findings shed new light on the therapeutic potential of HDACibased intervention for neurocognitive disorders, demonstrating that the molecular response to treatment is likely to vary dramatically in relation to ongoing experience.

\section{Materials and Methods}

Experimental design overview

Experiment 1 examined the effects of experience and HDACi administration on mRNA expression in the young rat hippocampus, and Experiment 2 comprised a parallel analysis of synaptic protein markers in a rodent model of normal cognitive aging. Animals in both experiments were initially trained on a standardized, hidden platform version of the Morris water maze used in many previous experiments (Gallagher et al., 1993; Haberman et al., 2011; Morrison and Baxter, 2012). Here, background training was used to document the status of hippocampal mem-

H.P. is an employee at FORUM Pharmaceuticals, which licenses one of the HDACi compounds used here. The remaining authors declare no competing financial interests.

Correspondence should be addressed to Dr. Peter R. Rapp, Laboratory of Behavioral Neuroscience, National Institute on Aging, 251 Bayview Blvd, Suite 100, Baltimore, MD 21224. E-mail: rappp@mail.nih.gov.

DOI:10.1523/JNEUROSCI.4339-14.2015

Copyright $\odot 2015$ the authors $\quad 0270-6474 / 15 / 3511730-14 \$ 15.00 / 0$ ory in young and aged rats and to provide a basis for configuring appropriately matched groups for subsequent HDACi treatment. One week later, subjects were tested, either with or without acute pretraining HDACi injection, on a one session redundant place-cue (RPC) variant of the water maze as an inducing event for examining hippocampal mRNA (Experiment 1) or synaptic protein expression (Experiment 2). The RPC procedure satisfied three important criteria for use in these experiments: (1) it robustly engages the hippocampus (Fletcher et al., 2006, 2014); (2) RPC training reveals experience-dependent histone acetylation dynamics in the hippocampus (Castellano et al., 2012); and (3) it is a sensitive assessment of age-related cognitive impairment (Fletcher et al., 2014). Animals were killed 90 min after RPC testing, with age-matched rats killed from the home cage serving as controls. Much longer retention intervals are needed to detect the reported procognitive benefits of HDACi administration (Levenson et al., 2004; Fischer et al., 2007; Lattal et al., 2007; Kilgore et al., 2010; Peleg et al., 2010); thus, the present experiments focusing on gene and protein expression were not optimized for assessing the effects of HDACi treatment on memory, per se. Across experiments, we examined two HDACi: suberoylanilide hydroxamic acid (SAHA; Experiment 1), as in previous studies (Guan et al., 2009; Kilgore et al., 2010; Peleg et al., 2010), and a second, novel hydroxamic acid-like HDACi (EVX001688 [EVX]; Experiment 2). In this way, we were able to test whether the modulatory influence of experience observed in Experiment 1 was a peculiarity and potentially off-target effect of SAHA. In addition, Experiment 2 took advantage of a compound that we previously confirmed is brain-penetrant and yields robust increases in hippocampal histone acetylation at $90 \mathrm{~min}$ following systemic injection in both young and aged rats (Castellano et al., 2014). By comparison, previous studies have frequently failed to document the efficacy of HDACi administration on the intended target (i.e., histone acetylation).

\section{Subjects}

A total of 76 male Fischer $344 \times$ Brown Norway F1 hybrid rats (F344xBN) were obtained from the National Institute on Aging colony (Harlan Industries). Twenty-eight mature young adults at 7 months of age were used for microarray analysis (Experiment 1), and both young (7-9 months, $n=19)$ and aged rats $(26-30$ months, $n=29)$ were used to examine synaptic protein markers in the hippocampus by immunocytochemistry (Experiment 2). Rats were singly housed in standard cages in a climate-controlled vivarium maintained on a $12 \mathrm{~h}$ light/dark cycle. Food and water were available ad libitum. Subjects acclimated for 1 week and were handled for $5 \mathrm{~min} / \mathrm{d}$ for a total of $3 \mathrm{~d}$ before treatment. Animal procedures followed the National Institutes of Health Guide for the Care and Use of Laboratory Animals (2011) and were approved by the Animal Care and Use Committee of the National Institute on Aging.

Groups in Experiment 1 consisted of home cage controls (HC) given SAHA (HDACi) or vehicle (Veh) injections $90 \mathrm{~min}$ before death $(\mathrm{HC}+\mathrm{Veh}$, and $\mathrm{HC}+\mathrm{HDACi} ; n=7$ each $)$ and parallel groups that additionally received $\mathrm{RPC}$ training following vehicle or $\mathrm{HDACi}$ administration (RPC + Veh, and $\mathrm{RPC}+\mathrm{HDACi} ; n=7$ per group). Experiment 2 was similar, except that we included both young adult and aged rats (young, 7-9 months; young $\mathrm{HC}+\mathrm{Veh}, n=6$; young $\mathrm{HC}+\mathrm{HDACi}, n=5$; young RPC $+\mathrm{HDACi}, n=8$; aged, 26-30 months; aged $\mathrm{HC}+\mathrm{Veh}, n=$ 11 ; aged $\mathrm{HC}+\mathrm{HDACi}, n=11$; aged RPC $+\mathrm{HDACi}, n=7)$. The effects of behavioral training alone on synaptic connectivity are subtle in magnitude and sparsely distributed, below the limits of detection by standard light microscopy immunocytochemical methods (Bailey and Kandel, 1993; Rusakov et al., 1997; Moser, 1999). Accordingly, vehicle-treated RPC groups were not included in Experiment 2.

\section{Water maze training}

Standard place training. Standard water maze training (for detailed description, see Gallagher et al., 1993) was conducted for all rats in Experiments 1 and 2, except for a subset of young and aged home cage controls. Briefly, training took place across 8 consecutive days, three trials per day (each using a $90 \mathrm{~s}$ cutoff), with a $60 \mathrm{~s}$ intertrial interval. Every sixth trial was a probe test in which the escape platform was initially retracted to the bottom of the maze for $30 \mathrm{~s}$ and then made accessible to permit escape. 
Performance was evaluated according to learning index scores (i.e., the weighted average proximity to the escape platform across probe trials), as described previously (Gallagher et al., 1993). By this measure, lower values reflect closer proximity to the escape location and better spatial learning.

$R P C$ training. One week following standard spatial training, subjects used to examine the influence of recent experience on the response to HDACi administration were tested on a one session RPC variant of the Morris water maze (Fletcher et al., 2006, 2014; Castellano et al., 2012, 2014). As noted earlier, this procedure was selected for the present experiments because it robustly engages the hippocampus, it is a sensitive setting for examining experience-dependent histone acetylation dynamics, and it reveals age-related cognitive impairment. Learning index scores from the standard place task were used to allocate rats such that spatial memory capacity was matched across groups. The RPC protocol included both hidden and cued (visible) goal trials, with the escape platform held in a fixed location throughout. The training protocol consisted of 17 trials ( $60 \mathrm{~s}$ cutoff), with a $15 \mathrm{~s}$ intertrial interval. During trials 1-9, $11,13,15$, and 17, a black escape platform protruded above the water surface, rendering it visible; and on trials $10,12,14$, and 16, the platform was hidden, submerged just below the water. A single $60 \mathrm{~s}$ probe trial was administered $85 \mathrm{~min}$ after the onset of training, immediately before death. The platform was inaccessible during the probe, and spatial bias for the escape location and the strategy used to guide navigation were assessed. Acquisition was evaluated as average path length to escape, and probe performance was assessed by average proximity to the goal location relative to an equivalent area in the opposite quadrant of the maze. A useful feature of this assessment in studies with aged animals is that key performance factors (e.g., sensorimotor demands) are reasonably well matched across age groups, but the design allows for learning based on a cue-approach strategy, learning the spatial location of the hidden escape platform, or both. Efficient escape to the submerged platform during probe testing requires spatial learning, providing an additional window on hippocampal integrity (Castellano et al., 2012, 2014; Fletcher et al., 2014). In the present experiments, RPC training served as a direct experimental manipulation to examine whether ongoing experience modulates the effects of HDACi administration on gene and protein expression in the hippocampus.

\section{Histone deacetylase inhibitor administration}

SAHA. SAHA (Selleckchem; catalog \#S1047), a hydroxamic acid type HDACi, inhibits Class I and II HDAC enzymes (Dokmanovic et al., 2007). Rats were injected with freshly prepared SAHA dissolved in $100 \%$ DMSO, administered at $50 \mathrm{mg} / \mathrm{kg}$ (final concentration delivered was 50 $\mathrm{mg} / \mathrm{ml}$ i.p.) per rat, or with an equal volume of $100 \%$ DMSO vehicle (Veh). The dose selected was previously reported to improve memory following pretraining administration (Kilgore et al., 2010; Fujita et al., 2012). Vehicle and SAHA solutions were administered $10 \mathrm{~min}$ before RPC testing, 90 min before death.

EVX. EVX (FORUM Pharmaceuticals) is a brain-penetrant HDACi that inhibits Classes I, IIb, and IV HDACs at nanomolar concentrations. EVX exhibits a profile of HDAC enzyme inhibition characteristic of a hydroxamic acid type HDACi like SAHA, with good target selectivity (Castellano et al., 2014). Young and aged rats were injected with freshly prepared EVX dissolved in 60\% Solutol HS 15 (BASF) and 40\% ethanol, diluted $1: 1$ with water to yield a $30 \mathrm{mg} / \mathrm{ml}$ solution, or an equivalent volume of the Solutol-ethanol-water vehicle (Veh). Injections were administered intraperitoneally $10 \mathrm{~min}$ before RPC training and $90 \mathrm{~min}$ before death. We recently reported that the EVX dose $(30 \mathrm{mg} / \mathrm{kg})$ and delivery schedule used here yield robust histone acetylation in the aged hippocampus and a numerically modest improvement in spatial memory in young rats relative to a lower dose (Castellano et al., 2014). The effects of EVX administration on synaptic protein expression, however, have not been examined previously.

\section{Microarray}

RNA isolation, microarray hybridization, and statistical analysis. Ninety minutes following injection of vehicle or SAHA, animals in all conditions were deeply anesthetized with isoflurane and killed. Brains were re- moved, and freshly microdissected hippocampal subfields (CA1, CA3, and dentate gyrus $[D G]$ ) were frozen and stored at $-80^{\circ} \mathrm{C}$. All procedures were conducted using RNase-free methods. Transcriptional profiling of hippocampal subregions was conducted using Illumina Sentrix beadchips. A $0.5 \mu \mathrm{g}$ aliquot of total RNA from each hippocampal subregion was used to produce biotin-labeled cRNA and was amplified using the Illumina TotalPrep RNA Amplification Kit. Briefly, total RNA was reverse transcribed into single-stranded cDNA using an oligo-dT primer, including the T7 RNA polymerase promoter site, and then copied to generate double-stranded cDNA molecules. The double-stranded cDNA was washed and concentrated with the supplied columns and subsequently used in an overnight in vitro transcription reaction where singlestranded RNA (cRNA) was produced incorporating biotin-16-UTP. A total of $0.75 \mu \mathrm{g}$ of RNA was hybridized at $58^{\circ} \mathrm{C}$ for $16 \mathrm{~h}$ to the RatRef- 12 Expression BeadChip array (Illumina). A single BeadChip contains $\sim 22,000$ RefSeq transcripts, representing the whole-genome, with a $\sim 30$-fold redundancy. The arrays were then washed, blocked, and incubated with streptavidin-Cy3. Subsequently, the arrays were scanned using a BeadStation 500X Genetic Analysis Systems scanner (Illumina), and the image data were extracted using the BeadStation GenomeStudio software, version 2.0 (Illumina).

In overview, the microarray data analytic pipeline consisted of the following steps: data filtering and normalization, quality control, detection of significant differential gene expression, and predicted functional analysis of significant genes. Specifically, raw microarray data were filtered based on the detection $p$ value $<0.02$ to remove genes that were not detected above background intensity levels across arrays. Using DIANE 6.0 , a spreadsheet-based microarray analysis program, the raw intensity data were then $\log _{10}$ transformed and used to calculate $Z$-scores (Cheadle et al., 2003). The $Z$-scores were determined by subtracting the overall average gene intensity from the raw intensity data for each gene, and then dividing that outcome by the SD of all of the measured intensities (Cheadle et al., 2003). Next, sample quality was analyzed by scatter plot, principal component analysis, and gene sample $Z$-score-based hierarchical clustering to exclude potential outliers. The potential modulatory influence of experience on the response to HDACi treatment was then evaluated in three planned contrasts, testing for differential gene expression between conditions: (1) "HDAC inhibition," testing the effect of drug alone, determined by differential gene expression between the $\mathrm{HC}+\mathrm{Veh}$ and HC+HDACi groups; (2) "experience," testing the effect of recent experience alone, determined by contrasting gene expression in the $\mathrm{HC}+\mathrm{Veh}$ and RPC+Veh groups; and (3) "experience + HDAC inhibition," testing the effect of HDACi administration provided in conjunction with behavioral training, determined by contrasting gene expression in the HC+HDACi and RPC+HDACi groups. $Z$-scores for these comparisons were analyzed using the $Z$-ratio statistic, which signifies the fold difference between experimental groups. The $Z$-ratio was determined by taking the difference between the averages of the observed gene $Z$-scores and dividing by the SD of all of the differences for that specific comparison (Cheadle et al., 2003). The genes were then refined by determining the false discovery rate, which accounts for the expected ratio of falsely rejected hypotheses. Genes were further analyzed using an ANOVA design to compare across groups. Expression differences for individual genes were considered significant if they met the following criteria: (1) a mean background-corrected signal intensity $>0$; (2) an absolute $Z$-ratio value $\geq 1.5$; (3) a false discovery rate value of $<0.30$ (Tusher et al., 2001); and (4) an ANOVA $p$ value $\leq 0.05$. Other comparisons yielded largely redundant results (e.g., differential gene expression between the $\mathrm{HC}+\mathrm{Veh}$ and RPC+HDACi groups), similar to the overall pattern reported here. To examine potential regional selectivity, the microarray results from microdissected CA1, CA3, and DG samples were analyzed separately, yielding a total of nine comparisons. The CA1 region was the most robustly regulated hippocampal area in relation to the key variables under investigation; and for presentation clarity, subsequent analysis focused predominantly on this region. Based on the above criteria, a total of 3681 unique genes were differentially expressed in one or more comparisons and were visually represented by dendograms, Venn diagrams, and analyzed by Ingenuity Pathway Analysis (IPA; Ingenuity Systems; www.ingenuity.com). Venn diagrams were prepared for each of the three 
principal fields of the hippocampus. In this analysis, many genes were regulated in more than one hippocampal region.

\section{IPA}

IPA was used to identify associated networks, pathways, and upregulated and downregulated molecules represented in the experience and experience + HDAC inhibition contrasts in the CA1 field of the hippocampus (i.e., the subfield revealing the greatest total number of regulated genes). Differentially expressed genes in the experience and experience + HDAC inhibition comparisons were mapped onto their matching gene object in the Ingenuity Knowledge Base (i.e., "focus gene"). Selected focus genes were then incorporated into associated molecular networks and canonical pathways, generated on the basis of information extracted from the Knowledge Base (Shanley et al., 2007). Fisher's exact test was used to determine the probability that each function assigned to a comparison was due to chance alone. For presentation purposes, the Results lists the top 5 significant networks and canonical pathways identified in the experience and experience + HDAC inhibition contrasts, based on their network score (negative log of $p$ value), and for pathways, their $p$ value and ratio rating (calculated as the number of genes in each group that mapped onto a given pathway divided by the total number of genes listed in that pathway). Additionally, the top ranked upregulated and downregulated molecules, according to significance levels, are reported for each comparison.

\section{Quantitative immunoblot analysis}

Tissue homogenization and fractionation. Microdissected hippocampal subregions CA1, CA3, and DG were homogenized in a hypotonic buffer (10 mM HEPES, $1.5 \mathrm{~mm} \mathrm{MgCl}_{2}, 10 \mathrm{~mm} \mathrm{KCl}, 2 \times$ protease inhibitor mixture, $2 \times$ phosphatase inhibitor mixture; Pierce) and $2 \mathrm{~mm}$ sodium butyrate. Samples were then incubated on ice for $30 \mathrm{~min}$ and centrifuged at 1000 relative centrifugal force $(\mathrm{RCF})$ at $4^{\circ} \mathrm{C}$ for $15 \mathrm{~min}$. The supernatant (cytoplasmic fraction) was collected, and SDS was added to make a $2 \%$ SDS solution and then stored at $-80^{\circ} \mathrm{C}$. The nuclear pellet was washed with hypotonic buffer and centrifuged at $1000 \mathrm{RCF}$ at $4^{\circ} \mathrm{C}$ for $15 \mathrm{~min}$. The pellet was resuspended in SDS to make a $2 \%$ concentration, sonicated, and stored at $-80^{\circ} \mathrm{C}$.

Quantitative immunoblotting. Total protein concentrations for nuclear samples were determined using a BCA Protein Assay kit (ThermoScientific), and equivalent amounts of protein for each brain region were loaded and separated by SDS-PAGE (NuPage Novex 10\% Bis-Tris; Invitrogen). Actin (Biovsion 3598-100; 1:1000) was used to normalize acetyl-H3 and acetyl-H4 levels (i.e., core histone protein modifications implicated in learning-related plasticity) across lanes. Primary antibodies were anti-acetyl histone $\mathrm{H} 3$ (acetyl-H3; recognizing acetylated lysine sites 9, 14, 18, and 23; Millipore 06-599; 1:5000) and anti-acetyl histone $\mathrm{H} 4$ (acetyl-H4; recognizing acetylated lysines 5, 8, 12, and 16; Millipore 06-866; 1:5000). All primary antibodies to acetylated histone proteins were extensively characterized for specificity via peptide arrays (ActivMotif) in our previous study (Castellano et al., 2012). Secondary antibodies were AlexaFlour-488 goat anti-mouse (A11029; 1:2500) and AlexaFlour-633 goat anti-rabbit (A21071; 1:2500). Immunoblots were scanned at a resolution of $100 \mu \mathrm{m} / \mathrm{pixel}$ on a Typhoon Trio Plus Scanner (GE Healthcare), and bands were analyzed using ImageQuant TL image analysis software (GE Healthcare). The data are presented as the average across replicate assays.

\section{Immunocytochemistry}

Ninety minutes following Veh or HDACi injection, animals used to examine synaptic protein expression (Experiment 2) were deeply anesthetized with isoflurane and perfused transcardially with ice-cold PBS, followed by $4 \%$ PFA. Brains were removed and postfixed in $4 \%$ PFA in PBS overnight at $4^{\circ} \mathrm{C}$. The tissue was then cryoprotected overnight in $10 \%$ glycerol followed by $20 \%$ glycerol overnight at $4^{\circ} \mathrm{C}$. Brains were frozen in 2-methylbutane and stored at $-80^{\circ} \mathrm{C}$ until sectioning. Two aged rats ( 1 vehicle and 1 HDACi-treated) were excluded from analysis due to large pituitary tumors. Histological sections were cut frozen in the coronal plane on a sliding microtome at a nominal thickness of $40 \mu \mathrm{m}$ in a 1-in-10 series through the anterior-posterior extent of the hippocampus. Tissue was washed in TBS, followed by antigen retrieval treatment in citrate buffer (Invitrogen) with microwave heating (30 s), and subsequent blocking in 5\% normal donkey serum with $0.3 \%$ Triton X-100 in TBS for $1 \mathrm{~h}$ at room temperature. The tissue was incubated with primary antibody in blocking buffer for $48 \mathrm{~h}$ at $4^{\circ} \mathrm{C}$. Primary antibodies were directed against synaptophysin (Millipore MAB368; 1:500), N-cadherin (Santa Cruz Biotechnology, K-20: sc-31030; 1:250), spinophilin (courtesy of Drs. Paul Allen and Paul Greengard; 1:200,000), and anti-acetyl histone H4 (Millipore 06-866; 1:500). All synaptic protein antibodies were tested for specificity by Western blot analysis. Each antibody recognized the predicted molecular weight and selective antigen, and the signal intensity increased when higher amounts of total protein were loaded (data not shown). Specificity has also been documented in other published studies (Allen et al., 1997; Gottschall et al., 2010). Tissue sections were washed with TBS before incubation with species appropriate secondary antibodies, AlexaFluor donkey anti-rabbit 488 (Invitrogen A-21206; 1:1000), donkey anti-goat 633 (Invitrogen A-21082; 1:1000), and donkey anti-mouse Cy3 (Jackson ImmunoResearch Laboratories; 715-165-150; 1:1000), for $2 \mathrm{~h}$ at room temperature followed by additional TBS washes. Tissue was subsequently mounted onto glass slides, allowed to dry, and coverslipped with ProLong Gold Antifade Reagent with DAPI counterstain (Invitrogen). All brains were processed in one immunostaining run for the synaptic proteins and two runs for acetylated histone protein (i.e., one including young Veh and young HDACi animals, and a second for aged Veh and aged HDACi rats), with an equivalent number of sections from each condition. Data from each run were normalized as the percentage of age-matched vehicle values to permit comparison between the effect of EVX in young and aged rats.

\section{Quantitative imaging}

Fluorescence immunolabeling was digitized using a Typhoon Trio Plus Scanner (GE Healthcare) at a resolution of $10 \mu \mathrm{m} /$ pixel, and 16-bit grayscale TIFF images were collected. Using ImageJ software (http://rsbweb. nih.gov/ij/), images were inverted and pseudocolored to assist in visualizing the regions of interest for analysis. All quantification of immunofluorescence labeling intensity, however, was conducted on the original underlying grayscale images. For each synaptic protein, CA1 and CA3 stratum radiatum, and the inner and middle portions of the molecular layer of the dorsal DG were traced. These anatomical regions represent major connectional zones of intrinsic hippocampal circuitry and input from the entorhinal cortex to the DG, respectively. Mean immunofluorescence intensity for each tracing was quantified from the original grayscale images across four sections that surveyed the dorsal hippocampus, spaced at $400 \mu \mathrm{m}$ intervals. To confirm the efficacy of HDACi treatment, CA1, CA3, and the upper blade of the DG were traced and mean immunofluorescence intensity for histone $\mathrm{H} 4$ acetylation was quantified across four sections through the dorsal hippocampus. Immunofluorescence intensity values for each marker were averaged across histological sections to compute a single value per animal for each label and anatomical region of interest. Our previous results are also noteworthy in this context, demonstrating by quantitative immunoblotting that the same HDACi used here yields robust acetylation of both histone $\mathrm{H} 3$ and $\mathrm{H} 4$ in the aged hippocampus (Castellano et al., 2014).

\section{Statistical analysis}

Parametric statistics (ANOVA, paired and unpaired two-tailed $t$ tests) were used to compare pertinent behavioral outcome measures across treatment conditions (Experiments 1 and 2), quantitative Western blot results for acetylated histone $\mathrm{H} 3$ and $\mathrm{H} 4$ protein levels (Experiment 1), and immunolabeling for synaptic and acetylated histone $\mathrm{H} 4$ protein levels (Experiment 2). Least significant difference (LSD) post hoc tests were used to compare measures between treatment conditions.

\section{Results}

\section{Experiment 1}

$R P C$ training results in strong memory for spatial location Subjects used to examine the effects of experience and HDACi treatment on gene expression were initially trained on a standard place version of the Morris water maze task. Rats were subsequently assigned to the RPC + Veh or RPC+HDACi conditions 
according to learning index scores such that performance was equivalent across groups (unpaired $t$ test: $t_{(12)}=-0.17, p=$ $0.87)$. One week following initial characterization, a one session RPC task was used to test whether water maze training modulates the gene expression response to HDACi administration in the young adult hippocampus. SAHA was administered $10 \mathrm{~min}$ before the RPC procedure, 90 min before death. Performance during training revealed that RPC + Veh- and RPC + HDACi-treated rats performed well on the first nine, cued trials with no effect of drug treatment (repeated-measures ANOVA; main effect of trials 1-9: $F_{(8,88)}=6.75, p \leq 0.0001$; main effect of drug: $F_{(1,11)}=0.06$, $p=0.81)$. The RPC + Veh and RPC + HDACi groups showed no differences in spatial acquisition as measured by the average difference in path length between trial 10, the first hidden trial, and trial 9, the last cued trial (unpaired $t$ test; $t_{(12)}=-0.38, p=0.71$ ). By this measure, low scores represent substantial transfer of spatial learning across the two trial types. During the probe trial, provided $\sim 85 \mathrm{~min}$ from the onset of training and immediately before death, both RPC+Veh- and RPC+HDACi-treated rats demonstrated strong spatial memory for the escape platform, with a lower mean proximity to the goal location compared with the center of the opposite quadrant (paired $t$ test; RPC+Veh: $t_{(6)}$ $=-7.01, p \leq 0.001$; RPC+HDACi: $\left.t_{(6)}=-8.31, p \leq 0.0001\right)$. As might be expected given their equivalent performance during acquisition, RPC+Veh- and RPC+HDACi-treated rats displayed comparable spatial memory for the escape platform location during the probe trial (unpaired $t$ test; $t_{(12)}=0.45, p=0.66$ ). These findings are consistent with reports that memory tested at a $1 \mathrm{~h}$ delay is insensitive to HDACi treatment (Levenson et al., 2004).

Hippocampal subregions exhibit distinct transcriptional profiles independent of treatment condition

Systemic SAHA injection ( $50 \mathrm{mg} / \mathrm{kg}$ ) induced a robust increase in hippocampal histone $\mathrm{H} 4$ acetylation levels 90 min after injection, although the more modest numerical increase in histone $\mathrm{H} 3$ acetylation was not statistically significant in the small number of animals examined (acetyl-H4: $t_{(6)}=-5.08, p \leq 0.01$; acetyl-H3: $t_{(6)}=-1.01, p=0.35$; Figure 1). Earlier studies have not routinely sought to confirm target efficacy for brain histone acetylation (for an exception, see Gräff et al., 2014), and it is noteworthy in this context that we also previously found a differential sensitivity of histone $\mathrm{H} 3$ and $\mathrm{H} 4$ proteins to $\mathrm{HDACi}$ administration (Castellano et al., 2014).

Because the hippocampus is composed of anatomically and molecularly distinct subfields that might mask regional or celltype specific differences when combined (Zhao et al., 2001), first we explored hippocampal subfield gene expression, independent of potential treatment effects. Global expression profiles were represented by dendrograms, generated by unsupervised hierarchical clustering, which arranges clusters according to the overall degree of similarity in transcriptional profiles. The highly segregated clusters observed across fields in all groups suggest that regional differences comprise a powerful drive on hippocampal gene expression (Fig. $2 A-D$ ), and that any effect of experience on the response to HDACi is presumably constrained by this underlying organization.

HDACi effects on global gene expression in hippocampus are experience-dependent

Subsequent analyses quantified differential gene expression in the hippocampus to test the influence of three experimental manipulations: (1) the effect of HDACi administration alone (HDAC inhibition; evaluated as differential expression between
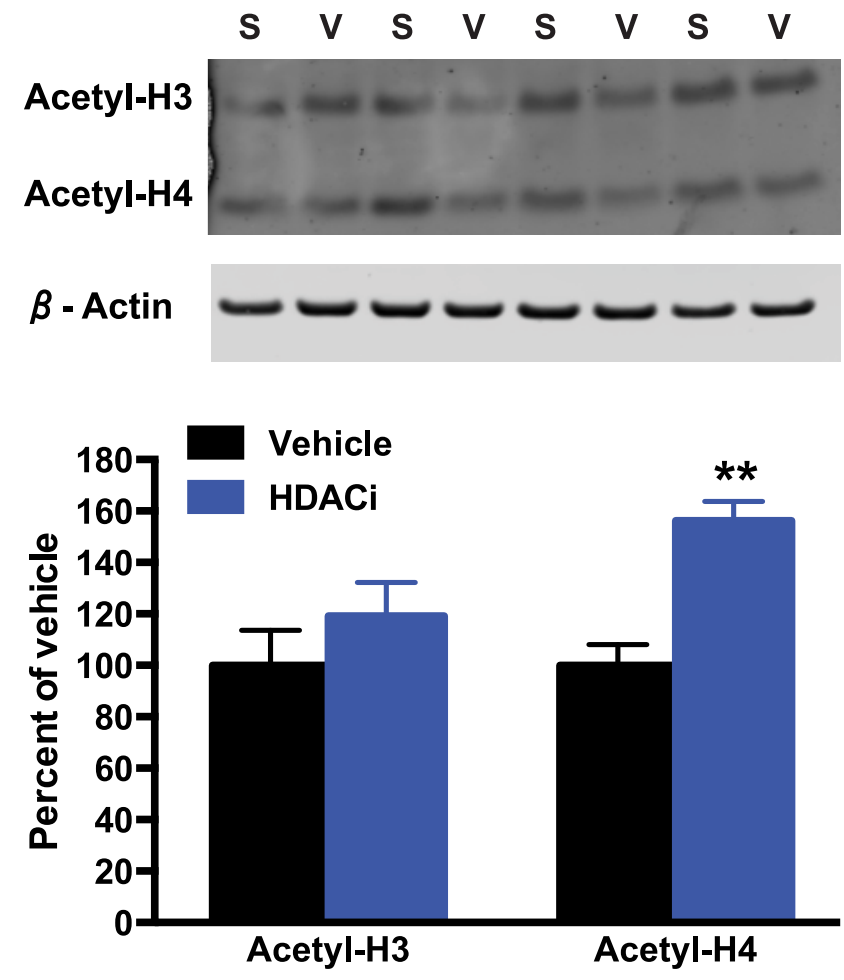

Figure 1. Acute systemic HDACi treatment increases hippocampal histone acetylation. Representative Western blots (top) and associated quantification (bottom) for acetylated histone $\mathrm{H} 3$ and $\mathrm{H} 4 \mathrm{in} \mathrm{CA} 3$ from young rats provided vehicle $(\mathrm{V} ; n=4)$ or $50 \mathrm{mg} / \mathrm{kg}$ of SAHA intraperitoneally $(S ; n=4) 90$ min before death. Animals used for this purpose were separate from those in the microarray analysis. Histone acetylation was normalized to $\beta$-actin, and the data are represented as the percentage of vehicle-treated values. Error bars indicate SEM. ${ }^{* *} p \leq 0.01$.

the $\mathrm{HC}+\mathrm{Veh}$ and $\mathrm{HC}+\mathrm{HDACi}$ conditions); (2) the effect of water maze training (experience; contrasting expression in the $\mathrm{HC}+\mathrm{Veh}$ and RPC+Veh groups); and (3) the modulatory influence of water maze training on the gene expression response to HDACi administration (experience + HDAC inhibition; contrasting expression in the $\mathrm{HC}+\mathrm{HDACi}$ and $\mathrm{RPC}+\mathrm{HDACi}$ groups). The total number of differentially regulated genes differed widely across these three contrasts, with the largest number influenced by the combination of training and HDACi treatment (experience + HDAC inhibition), and the fewest by HDACi treatment alone (HDAC inhibition) (i.e., a total of 2948 vs 259 genes, respectively, summed across hippocampal subfields; Fig. $3 A-C)$. RPC training alone regulated an intermediate number of genes (i.e., a total of 1769; Fig. 3A-C). The rank order of differential gene regulation across conditions was the same in all hippocampal subfields (experience + HDAC inhibition $>$ experience $>$ HDAC inhibition), but there were marked regional differences in the number of genes regulated across comparisons. Specifically, independent of treatment condition, CA1 displayed the highest total number of upregulated and downregulated genes (2966), followed by DG (1006), and CA3 (676). The DG and CA1 were equally sensitive to HDACi treatment alone (117 and 116 genes, respectively) and exhibited substantially greater regulation than CA3 (26 genes). These findings indicate that regional specificity conditions the influence of experience on the gene expression response to HDACi administration.

The effect of behavioral training, alone or in combination with HDACi injection, accounted for nearly $95 \%$ of all differentially regulated genes ( $96 \%$ in both CA1 and CA3, and $89 \%$ in DG; Fig. $3 A-C)$. In contrast, only $5 \%$ of the observed regulation 
A HC+Veh

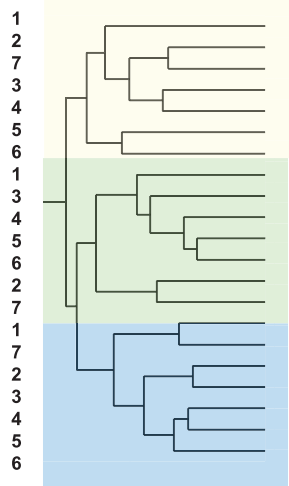

C

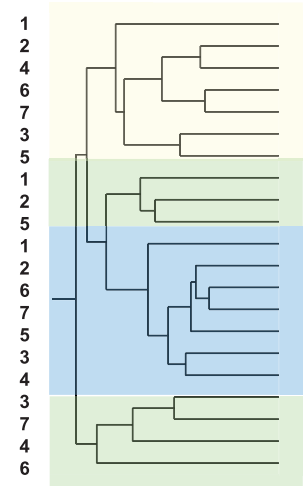

B

HC+HDACi

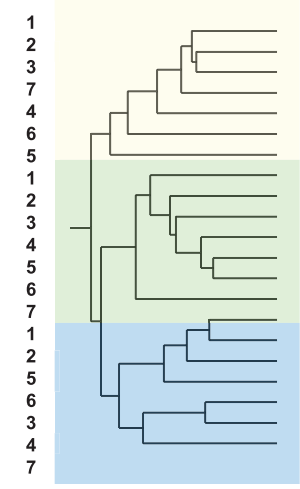

D RPC+HDACi

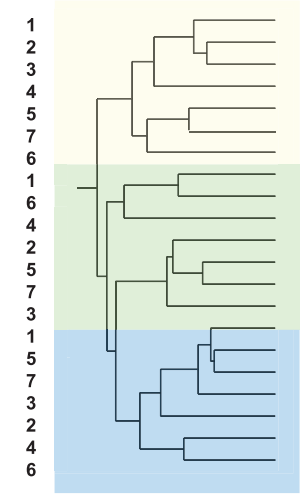

$\triangle$ CA1 $\square$ CA3 $\square$ DG

Figure 2. Hierarchical clustering analysis of global gene expression strongly segregates hippocampal subregions. Unsupervised hierarchical clustering of gene expression profiles in CA1, CA3, and the DG for each treatment condition. $A, H C+$ Veh $(n=7) . B, H C+H D A C i ~(n=7) . C$, $\mathrm{RPC}+\operatorname{Veh}(n=7) \cdot \boldsymbol{D}, \mathrm{RPC}+\mathrm{HDACi}(n=7)$. Numerals $1-7$ refer to the individual rats in each treatment condition.

was attributable to HDACi administration alone. These findings raised the possibility that behavioral training itself, independent of HDACi administration, was the main factor responsible for the large number of genes regulated in the experience + HDAC inhibition contrast. A priori, HDACi administration might also be predicted to disproportionately influence expression of the genes regulated by behavioral training, rather than inducing a qualitatively distinct transcriptional profile. To address these issues, we determined the number of genes that were shared and coregulated versus uniquely regulated across the experience and experience + HDAC inhibition contrasts (Fig. 3). Whereas $<7 \%$ of the genes identified were regulated in both contrasts (ranging from $5 \%$ in CA1 and CA3 to $14 \%$ in DG), the remaining $93 \%$ were uniquely regulated in relation to whether or not RPC training was provided in conjunction with HDACi treatment (Fig. 3A-C). Thus, the vast majority of differential gene regulation in the experience + HDAC inhibition contrast is distinct from the regulation attributable to RPC training and reflects the unique interactive influence of recent experience on the molecular response to HDACi administration. A similar pattern was found for individual gene classes, where a cluster analysis for nervous system development related genes (GO:0007399), for example, demonstrated that expression profiles in the HDAC inhibition and experience contrasts were clearly distinguished from the experience + HDAC inhibition comparison (data not shown). Together, these findings suggest that behavioral training provided in conjunction with HDACi administration induces a largely unique pattern of hippocampal gene expression and that experience-dependent signaling critically conditions the transcriptional response to pharmacologically elevated histone acetylation. The significant implication in the context of potential therapeutic applications is that the cell biological response to HDACi treatment may be difficult to predict and could vary widely across individuals in association with environmental influences, experiential history, and other subject-specific background characteristics.

IPA confirms that experience and experience + HDAC inhibition induce distinct gene expression profiles in CA1

Guided by our results for the aggregate pattern of regulation, next we focused on the most transcriptionally responsive field of the hippocampus (i.e., CA1) and used IPA as an exploratory tool for examining the range of biological functions modulated by experience alone (experience; 1287 genes), and the interaction between experience and HDAC inhibition (experience + HDAC inhibition; 1723 genes). IPA integrates genomic data with data mining methods to identify known functions and interconnectivity of genes extracted from the literature and included in the Ingenuity Knowledge Base. For the clarity of presentation, here we focus on the top 5 networks and canonical pathways (metabolic and signaling), and the top 10 upregulated and downregulated molecules that are differentially regulated in the experience, and experience + HDAC inhibition contrasts (Tables 1, 2, and 3; full microarray datasets for regulated gene networks, canonical pathways, and molecules will be deposited in the Gene Expression Omnibus DataSets; GEO). Statistical significance was determined by comparing the number of differentially expressed "focus genes" in each comparison (i.e., genes present in the Ingenuity Knowledge Base) with the number of eligible genes represented in a given network, pathway, or biological function. The greater the proportion of focus genes represented, the higher the significance value. As shown in Table 1, the highest scoring networks associated with focus genes regulated by experience alone (experience), and by experience in conjunction with HDACi treatment (experience + HDAC inhibition), are substantially nonoverlapping, and the breadth of biological functions involved is extensive in both conditions. These findings suggest that the cell biological response to ongoing experience is qualitatively modified, not simply amplified or enhanced, by HDACi administration.

Canonical pathway analysis for CA1 revealed an extensive range of pathways significantly regulated by experience (total of 256 pathways) and experience + HDAC inhibition (total of 276; for top 5 pathways, see Table 2). Like the other levels of data exploration, this approach revealed relatively little overlap between contrasts. Top differentially regulated pathways identified in the experience + HDAC inhibition condition notably included a number directly implicated in memory-related plasticity and that were not as highly ranked in the RPC alone comparison (i.e., cAMP-mediated signaling and synaptic long-term potentiation) (Kandel, 2012; Bannerman et al., 2014). A similarly broad profile was observed for the top molecules upregulated or downregulated (Table 3), where both contrasts prominently included, but were not restricted to, genes implicated in synaptic plasticity and memory (e.g., Arc, NR4A2 and Jun) (Guzowski et al., 2000; Alberini, 2009; Hawk and Abel, 2011).

Further data mining revealed a similar pattern among the top 10 biological processes specifically filtered for memory and epigenetic-related functions (filtered by the terms neuro, hip- 
A

CA1

HDAC Inhibition

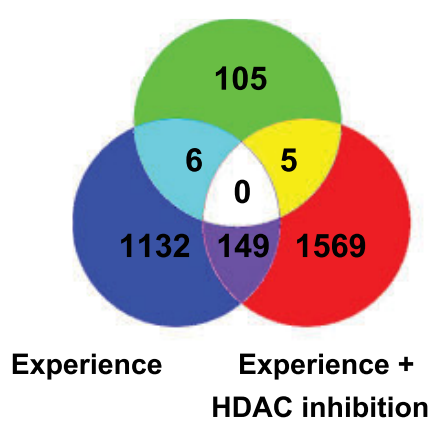

B

CA3

HDAC Inhibition

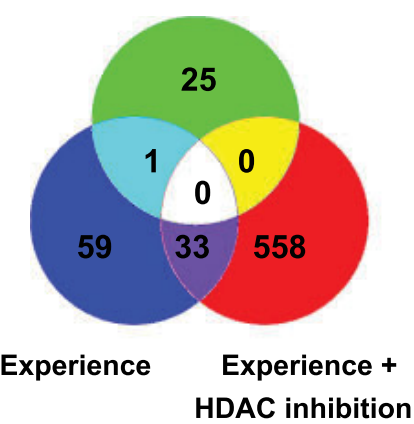

C

DG

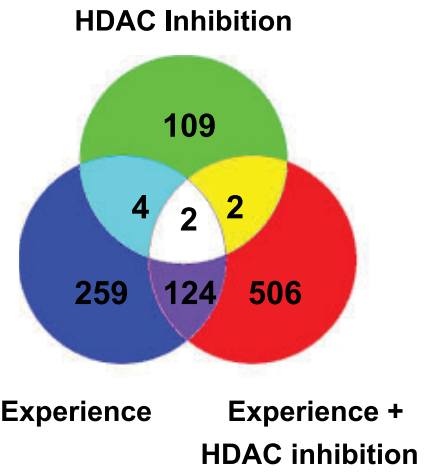

Figure 3. Venn diagram classification of the number of differentially regulated genes across key contrasts in $C A 1, C A 3$, and $D G$. The three circles in each diagram list the number of genes differentially upregulated or downregulated by HDAC inhibition ( $\mathrm{HC}+$ Veh vs $\mathrm{HC}+\mathrm{HDACi}$ contrast), experience (HC + Veh vs RPC + Veh contrast), or the combination of both experience + HDAC inhibition (RPC + Veh vs RPC + HDACi contrast), with genes regulated in multiple contrasts represented in the corresponding intersection between circles. For all hippocampal subregions, the greatest numbers of differentially regulated genes were observed in the experience + HDAC inhibition contrast, and relatively few were coregulated in multiple conditions. $A$, CA1. B, CA3. C, DG.

Table 1. Top five regulated networks in experience and experience + HDAC inhibition contrasts in CA1 $^{a}$

\begin{tabular}{|c|c|c|c|}
\hline & \multicolumn{3}{|c|}{ Top networks } \\
\hline & ID & Associated network functions & Score \\
\hline \multirow[t]{5}{*}{ Experience } & 1 & Gene expression, cellular growth and proliferation, cell death and survival & 131 \\
\hline & 2 & Developmental disorder, neurological disease, psychological disorders & 81 \\
\hline & 3 & Cell morphology, cellular function and maintenance, molecular transport & 55 \\
\hline & 4 & Behavior, cell-to-cell signaling and interaction, nervous system development and function & 43 \\
\hline & 5 & Hereditary disorder, neurological disease, skeletal and muscular disorders & 37 \\
\hline \multirow[t]{5}{*}{ Experience + HDAC inhibition } & 1 & Cellular development, cell death and survival, cellular movement & 113 \\
\hline & 2 & Neurological disease, cell-to-cell signaling and interaction, nervous system development and function & 113 \\
\hline & 3 & Hereditary disorder, neurological disease, skeletal and muscular disorders & 113 \\
\hline & 4 & Cell death and survival, cell cycle, gene expression & 38 \\
\hline & 5 & Cell cycle, reproductive system development and function, nervous system development and function & 38 \\
\hline
\end{tabular}

${ }^{a}$ Data obtained from IPA; the score represents the negative log of $p$ value of the Fisher's exact test.

Table 2. Top five regulated canonical pathways in experience and experience + HDAC inhibition contrasts in CA1 ${ }^{a}$

\begin{tabular}{|c|c|c|c|}
\hline & Top canonical pathways & $p$ value & Ratio \\
\hline \multirow[t]{5}{*}{ Experience } & NRF2-mediated oxidative stress response & 1.47E-03 & $24 / 106(0.226)$ \\
\hline & Superoxide radicals degradation & $6.36 \mathrm{E}-03$ & $3 / 4(0.75)$ \\
\hline & Rac signaling & 7.87E-03 & $16 / 70(0.229)$ \\
\hline & RhoA signaling & $1.04 \mathrm{E}-02$ & $14 / 60(0.233)$ \\
\hline & Signaling by Rho family GTPases & $1.09 \mathrm{E}-02$ & $24 / 123(0.195)$ \\
\hline \multirow[t]{5}{*}{ Experience + HDAC inhibition } & cAMP-mediated signaling & $2.32 \mathrm{E}-05$ & $39 / 123(0.317)$ \\
\hline & Neuropathic pain signaling in dorsal horn neurons & $8.00 \mathrm{E}-05$ & $24 / 66(0.364)$ \\
\hline & Cellular effects of sildenafil (Viagra) & 1.37E-04 & $22 / 60(0.367)$ \\
\hline & Role of NFAT in cardiac hypertrophy & $2.60 \mathrm{E}-04$ & $33 / 109(0.303)$ \\
\hline & Synaptic long-term potentiation & $2.71 \mathrm{E}-04$ & $26 / 79(0.329)$ \\
\hline
\end{tabular}

${ }^{a}$ Data obtained from IPA; the $p$ value is of the Fisher's exact test, and the ratio represents the number of genes in each group that maps onto a given pathway divided by the total number of genes listed in that pathway.

pocampus, behavior, learning, memory, and epigenetics; Fig. $4 A, B)$. A noteworthy outcome of this analysis is that water maze training increased the diversity of HDACi-induced regulation. For example, whereas the top 4 categories comprised $>80 \%$ of the genes identified in the experience contrast, approximately the same percentage was distributed across the top 7 biological processes in the experience + HDAC inhibition comparison. Together, the findings are compelling that ongoing experience potently modulates the molecular response to elevated histone acetylation in the hippocampus. Our next experiment extended these observations to examine the interactive influence of experience and HDACi treatment on connectional plasticity in key hippocampal circuits in a naturally occurring model of memory impairment in aged rats.

\section{Experiment 2}

Water maze training reveals age-related spatial memory impairment

Experiment 2 tested whether experience influences the hippocampal synaptic protein response to HDACi administration in a rat model of cognitive aging. The design was similar to Experiment 1, except we tested a second HDACi (EVX; FORUM Pharmaceuticals) previously confirmed to yield robust histone $\mathrm{H} 3$ and $\mathrm{H} 4$ acetylation in the aged hippocampus (Castellano et al., 
Table 3. Top 10 upregulated and downregulated molecules in experience and experience + HDAC inhibition contrasts in CA1 ${ }^{a}$

\begin{tabular}{|c|c|c|c|c|c|}
\hline & Molecule & Entrez gene name & Log ratio & Location & Type(s) \\
\hline \multirow[t]{22}{*}{ Experience } & \multicolumn{5}{|l|}{ Log ratio upregulated } \\
\hline & MARCKS & Myristoylated alanine-rich protein kinase C substrate & 7.26 & Plasma membrane & Other \\
\hline & ARC & Activity-regulated cytoskeleton-associated protein & 6.67 & Cytoplasm & Other \\
\hline & CPE & Carboxypeptidase E & 6.51 & Plasma membrane & Peptidase \\
\hline & ANKS1B & Ankyrin repeat and sterile alpha motif domain containing $1 \mathrm{~B}$ & 6.44 & Nucleus & Other \\
\hline & NR4A2 & Nuclear receptor subfamily 4, group A, member 2 & 6.42 & Nucleus & $\begin{array}{l}\text { Ligand-dependent } \\
\text { nuclear receptor }\end{array}$ \\
\hline & MAP2 & Microtubule-associated protein 2 & 6.32 & Cytoplasm & Other \\
\hline & ATP6V1A & ATPase, $\mathrm{H}^{+}$transporting, lysosomal $70 \mathrm{kDa}$, V1 subunit A & 6.19 & Cytoplasm & Transporter \\
\hline & AQP4 & Aquaporin 4 & 6.14 & Plasma membrane & Transporter \\
\hline & MAGI2 & $\begin{array}{l}\text { Membrane-associated guanylate kinase, WW and } \\
\text { PDZ domain containing } 2\end{array}$ & 6.09 & Plasma membrane & Kinase \\
\hline & ATAD1 & ATPase family, AAA domain containing 1 & 5.96 & Cytoplasm & Enzyme \\
\hline & \multicolumn{5}{|l|}{ Log ratio downregulated } \\
\hline & SH3BGRL3 & SH3 domain binding glutamic acid-rich protein like 3 & -4.77 & Nucleus & Other \\
\hline & FAT4 & FAT tumor suppressor homolog 4 (Drosophila) & -4.19 & Unknown & Other \\
\hline & PYCRL & Pyrroline-5-carboxylate reductase-like & -3.7 & Unknown & Enzyme \\
\hline & JUN & Jun proto-oncogene & -3.56 & Nucleus & Transcription regulator \\
\hline & ATP6V0A1 & ATPase, $\mathrm{H}^{+}$transporting, lysosomal V0 subunit a1 & -3.5 & Cytoplasm & Transporter \\
\hline & MRPL23 & Mitochondrial ribosomal protein L23 & -3.43 & Cytoplasm & Other \\
\hline & DDIT3 & DNA-damage-inducible transcript 3 & -3.37 & Nucleus & Transcription regulator \\
\hline & ITPA & Inosine triphosphatase (nucleoside triphosphate pyrophosphatase) & -3.35 & Cytoplasm & Enzyme \\
\hline & C2CD2L & C2CD2-like & -3.18 & Unknown & Other \\
\hline & ATP1A3 & ATPase, $\mathrm{Na}^{+} / \mathrm{K}^{+}$transporting, alpha 3 polypeptide & -3.18 & Plasma membrane & Transporter \\
\hline Experience + HDAC & Log ratio upregulated & & & & \\
\hline \multirow{21}{*}{ inhibition } & NTS & Neurotensin & 8.41 & Extracellular space & Other \\
\hline & LUM & Lumican & 8.39 & Extracellular space & Other \\
\hline & MEIS2 & Meis homeobox 2 & 7.17 & Nucleus & Transcription regulator \\
\hline & MOBP & Myelin-associated oligodendrocyte basic protein & 5.9 & Cytoplasm & Other \\
\hline & HTR7 & $\begin{array}{l}\text { 5-hydroxytryptamine (serotonin) receptor 7, adenylate } \\
\text { cyclase-coupled }\end{array}$ & 5.89 & Plasma membrane & $\begin{array}{l}\text { G-protein coupled } \\
\text { receptor }\end{array}$ \\
\hline & KLK6 & Kallikrein-related peptidase 6 & 5.69 & Extracellular space & Peptidase \\
\hline & TAC1 & Tachykinin, precursor 1 & 5.53 & Extracellular space & Other \\
\hline & GRP & Gastrin-releasing peptide & 5.52 & Extracellular space & Growth factor \\
\hline & HS3ST2 & Heparan sulfate (glucosamine) 3-0-sulfotransferase 2 & 5.47 & Cytoplasm & Enzyme \\
\hline & MOG & Myelin oligodendrocyte glycoprotein & 5.38 & Extracellular space & Other \\
\hline & \multicolumn{5}{|l|}{ Log ratio downregulated } \\
\hline & GRM2 & Glutamate receptor, metabotropic 2 & -9.1 & Plasma membrane & $\begin{array}{l}\text { G-protein coupled } \\
\text { receptor }\end{array}$ \\
\hline & TIAM1 & T-cell lymphoma invasion and metastasis 1 & -8.96 & Cytoplasm & Other \\
\hline & $\operatorname{CCDC85A}$ & Coiled-coil domain containing 85A & -8.17 & Unknown & Other \\
\hline & PDYN & Prodynorphin & -8.15 & Extracellular space & Transporter \\
\hline & PERP & PERP, TP53 apoptosis effector & -7.98 & Plasma membrane & Other \\
\hline & GPC4 & Glypican 4 & -7.67 & Plasma membrane & $\begin{array}{l}\text { Transmembrane } \\
\text { receptor }\end{array}$ \\
\hline & RASL10A & RAS-like, family 10 , member A & -7.62 & Nucleus & Enzyme \\
\hline & KISS1R & KISS1 receptor & -7.15 & Plasma membrane & $\begin{array}{l}\text { G-protein coupled } \\
\text { receptor }\end{array}$ \\
\hline & RGS9 (includes EG:19739) & Regulator of G-protein signaling 9 & -6.78 & Cytoplasm & Enzyme \\
\hline & SYNPR & Synaptoporin & -6.74 & Plasma membrane & Transporter \\
\hline
\end{tabular}

${ }^{a}$ Data obtained from IPA; log ratios represent fold change.

2014). Because behavioral training alone fails to induce synaptic protein expression detectable by light microscopy (Bailey and Kandel, 1993; Rusakov et al., 1997; Moser, 1999), vehicle-treated RPC rats were not included. The experimental groups therefore comprised young and aged home cage controls (HC) treated with vehicle or HDACi (young, 7-9 months; young $\mathrm{HC}+\mathrm{Veh}, n=6$; young $\mathrm{HC}+\mathrm{HDACi}, n=5$; aged, 26-30 months; aged $\mathrm{HC}+\mathrm{Veh}$, $n=11$; aged $\mathrm{HC}+\mathrm{HDACi}, n=11$ ), and parallel groups provided $\mathrm{RPC}$ training following HDACi treatment (young RPC $+\mathrm{HDACi}$, $n=8$; aged RPC+HDACi, $n=7)$.

Except for a subset of home cage controls, young and aged rats were initially tested on our standardized place version of the
Morris water maze, as described in Experiment 1. On average, aged rats displayed higher learning index scores compared with young adults (unpaired $t$ test: $t_{(17)}=2.46, p \leq 0.05$; Fig. $5 A$ ), reflecting longer average distances from the hidden platform and impaired memory for the escape location.

One week following initial water maze characterization, RPC training was used to test whether ongoing experience regulates the synaptic protein response to HDACi administration in the young and aged hippocampus. EVX was administered $10 \mathrm{~min}$ before the start of RPC testing (i.e., a time point 90 min before death). Young and aged rats swam directly to the visible escape platform across the first nine trials, without a substantial learning 
A

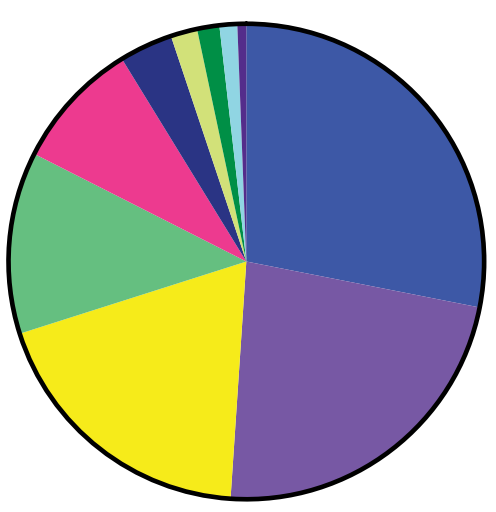

Experience

B

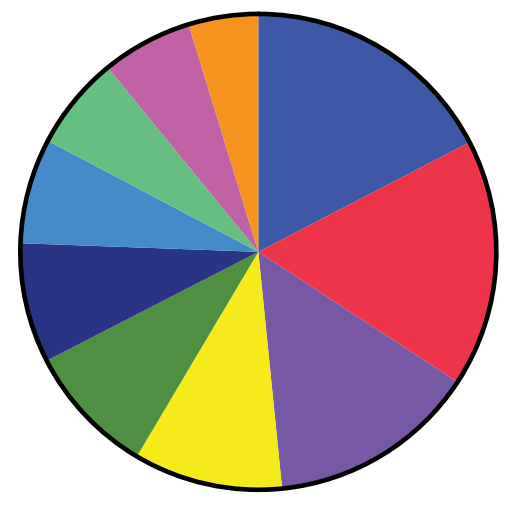

$\square 28.10 \%$ neuromuscular disease

$22.96 \%$ neurological signs

$19.03 \%$ neuronal cell death

$12.39 \%$ apoptosis of neurons

$8.76 \%$ migration of neurons

$3.63 \%$ development of hippocampus

$1.81 \%$ demyelinating peripheral neuropathy

$1.51 \%$ cell movement of cortical neurons

$1.21 \%$ development of hippocampal neurons

$0.60 \%$ stress response of neurons

\section{Experience + HDAC Inhibition}

Figure 4. Experience and experience $+\mathrm{HDAC}$ inhibition regulate largely distinct neuro-related gene families and inferred biological processes. Pie charts representing the percentage distribution of the top 10 biological processes regulated by experience $(H C+V$ eh vs RPC + Veh) $(\boldsymbol{A})$ and experience + HDAC inhibition $(H C+H D A C i v s R P C+H D A C i)(B)$ in CA1 (filtered for the terms neuro, hippocampus, behavior, learning, memory, and epigenetics).

curve, and the young rats scored better than aged animals (repeated-measures ANOVA; main effect of trials 1-9: $F_{(8,80)}=$ $0.47, p=0.88$; main effect of age: $F_{(1,10)}=4.87, p \leq 0.05$; Figure $5 B)$. The degree of spatial learning acquired during training was measured as the average difference in path length between the last cued and first hidden platform trials (Trials 9 and 10, respectively; Fig. 5B). Lower values reflect greater transfer across the two trial types and therefore better spatial learning for the escape location. Young rats displayed almost complete transfer, significantly outscoring aged subjects (unpaired $t$ test; $t_{(11)}=-2.89$, $p \leq 0.05)$. Age-related differences were also prominent on the probe test provided $\sim 1 \mathrm{~h}$ after training, just before death (Fig. $5 C)$. Young rats demonstrated a strong bias for the goal location relative to the opposite quadrant (paired $t$ test; $t_{(7)}=-3.88, p \leq$ 0.01 ), whereas aged rats exhibited no spatial memory (paired $t$ test; $t_{(6)}=0.59, p=0.58$ ). Direct comparison of proximity to the goal between the young and aged groups during probe testing also confirmed a reliable age-related impairment (unpaired $t$ test; $\left.t_{(13)}=-3.39, p \leq 0.01\right)$. Although our design necessitated using a shorter retention interval than optimal for detecting potential procognitive benefits of HDACi administration, the absence of significant spatial memory among the aged subjects suggests that EVX treatment failed to rescue age-related impairment, consistent with earlier findings (Castellano et al., 2014).
Acute pretraining HDACi administration enhances synaptic protein expression in the young adult, but not aged hippocampus Dynamic changes in synaptic connectivity are widely held to play a critical role in the plasticity necessary for normal memory (Kandel et al., 2014). Guided by previous reports linking HDACi administration with enhanced synaptic protein expression and dendritic spine number (Fischer et al., 2007; Guan et al., 2009; Gräff et al., 2014), here we used a similar immunocytochemical approach to evaluate whether recent experience dynamically regulates synaptic protein levels in response to HDACi administration in key hippocampal connectional zones in young and aged rats. We previously documented that systemic EVX injection induces histone acetylation in the aged Long-Evans hippocampus (Castellano et al., 2014), and we confirmed those findings here for young and aged F344xBN rats using immunofluorescence labeling in hippocampal subregions CA1, CA3, and DG (Fig. 6). Specifically, staining intensity for acetylated histone $\mathrm{H} 4$ was significantly increased in all hippocampal cell layers in both young and aged HDACi treated rats relative to age-matched vehicle controls (unpaired $t$ tests; all $p$ values $\leq 0.05$; Fig. 6 ). Although young rats displayed a numerically greater acetylation response to treatment than aged subjects (a difference averaging 5\%-8\% across hippocampal fields), this effect was not statistically significant in any region examined (unpaired $t$ tests for the young 
A

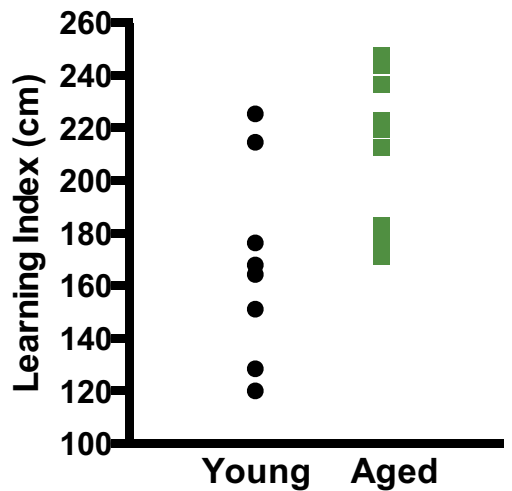

B

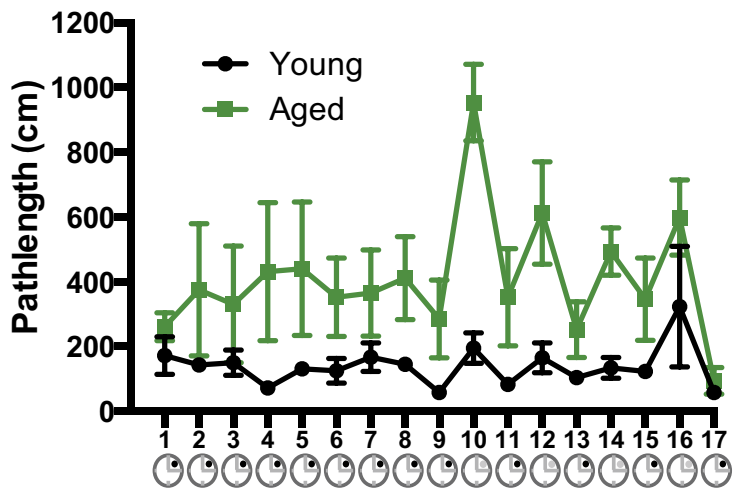

C

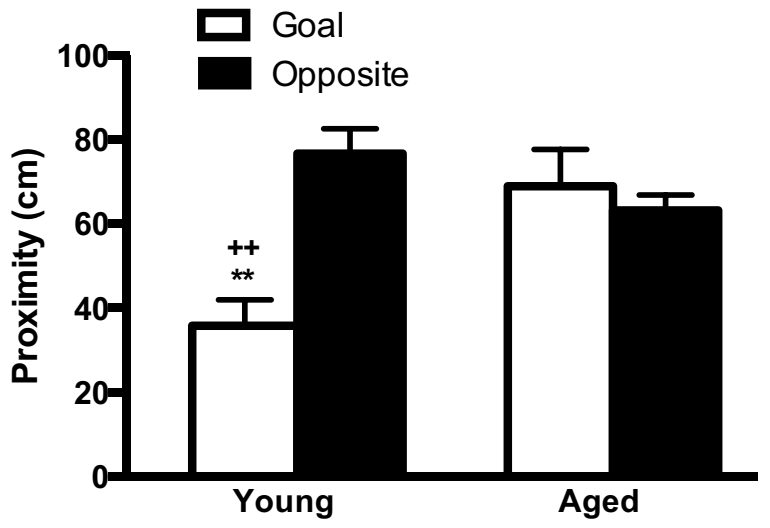

Figure 5. Behavioral characterization for young and aged rats used to examine synaptic protein expression. $A$, Learning index scores from a standardized spatial version of the water maze in individual young $(n=8)$ and aged $(n=11)$ rats. $\boldsymbol{B}, \mathrm{RPC}$ acquisition measured as mean path length to locate the escape platform after pretraining HDACi administration (EVX $30 \mathrm{mg} /$ kg, i.p.; young, $n=8$; aged, $n=7$ ). Schematic below the $x$-axis represents the escape platform location and whether it was visible (black) or hidden (gray) on each trial. C, Retention for the escape location during a probe test $85 \mathrm{~min}$ after training onset, expressed as mean proximity to the center of the goal and opposite quadrants (i.e., lower proximity to the goal reflects better spatial memory). Error bars indicate SEM. ${ }^{* *} p \leq 0.01$, relative to opposite quadrant. ${ }^{++} p \leq$ 0.01 , relative to aged rats.

$\mathrm{HC}+\mathrm{HDACi}$ versus Aged $\mathrm{HC}+\mathrm{HDACi}$ comparisons; all $p$ values $\geq 0.05$ ).

Representative pseudo-colored images of synaptophysin, $\mathrm{N}$-cadherin, and spinophilin immunoreactivity illustrate the pattern of labeling in the principal connectional zones of hippocampal circuitry across treatment conditions (Fig. 7A). In young rats, HDACi administration alone failed to modulate immunolabeling for synaptophysin, $\mathrm{N}$-cadherin, or spinophilin protein expression in any area of the hippocampus relative to $\mathrm{HC}+\mathrm{Veh}$ values (Fig. 7B, left panels). Indeed, among young $\mathrm{HC}+\mathrm{HDACi}$ animals, synaptophysin labeling showed a numerical decrease compared with vehicle controls (an average difference of 4\%-5\% across hippocampal fields). In contrast, among all age and treatment conditions, immunofluorescence intensity for all connectivity markers was numerically greatest in young rats that received behavioral training in conjunction with HDACi injection (i.e., young RPC+HDACi), with the exception of synaptophysin in DG. Consistent with this summary description, spinophilin labeling was significantly greater in young $\mathrm{RPC}+\mathrm{HDACi}$ rats compared with young $\mathrm{HC}+\mathrm{HDACi}$ animals in CA1 (main effect of group for young, $F_{(2,16)}=4.87, p \leq 0.05$; LSD post hoc contrast between young $\mathrm{HC}+\mathrm{HDACi}$ and young $\mathrm{RPC}+\mathrm{HDACi}$ groups, $p \leq 0.01)$ and CA3 $\left(F_{(2,16)}=7.11, p \leq\right.$ 0.01 ; LSD post hoc, $p \leq 0.01)$, with a similar trend in DG $\left(F_{(2,16)}=\right.$ $3.12, p=0.07$; LSD post hoc, $p \leq 0.05$ ) (Fig. $7 B$ ). The pattern was comparable for $\mathrm{N}$-cadherin staining intensity in young rats where we found marginally significant overall group effects in the CA1 and CA3 fields (main effect of group in CA1, $F_{(2,16)}=3.24, p=$ 0.07 ; LSD post hoc, $p=0.06$ and CA3, $F_{(2,16)}=2.89, p=0.09$; LSD post hoc, $p=0.07$ ) (Fig. $7 B$ ). Like the results for gene expression (Experiment 1), these findings suggest that the enhanced synaptic plasticity and protein expression reported in earlier studies of HDACi treatment (Gräff et al., 2011) require experience-dependent signaling. It is noteworthy in this context that the relevant background work in this area has typically been conducted in animals provided extensive recent behavioral experience (Levenson et al., 2004; Fischer et al., 2007; Peleg et al., 2010).

In contrast to the results for young rats, there was no indication of an HDACi effect on synaptic protein immunolabeling in the aged hippocampus under any condition (Fig. 7B). Indeed, values for the marker that proved most sensitive in young rats (i.e., spinophilin) were virtually identical among aged rats regardless of treatment, in all hippocampal fields. Extending earlier, related findings (Peleg et al., 2010; Castellano et al., 2012), these results suggest that the capacity for the epigenetic regulation of experience-dependent synaptic plasticity is disrupted in the aged hippocampus.

\section{Discussion}

Histone acetylation dynamics serve as an important molecular interface mediating environmental influences on neuronal gene and protein expression. The overall conclusion from the experiments reported here is that ongoing experience powerfully regulates the downstream consequences of pharmacologically prolonging histone acetylation levels in the hippocampus and that this interaction is significantly disrupted in aging. Microarray analysis revealed that HDACi administration alone, at a dosage we confirmed yields a significant increase in hippocampal histone acetylation, produces only modest effects on transcription as gauged by the total numbers of genes regulated. Nearly 10 times that number were regulated when an $\sim 15$ min bout of water maze training was provided in conjunction with HDACi treatment; and although behavioral testing itself also produced significant regulation, the specific genes and gene networks involved were largely nonoverlapping. Thus, the potent influence of cognitive experience on the gene expression response to elevated histone acetylation levels in the hippocampus comprises a qualitatively unique, synergistic interaction, and not simply the amplification of the transcriptional profile normally induced by experience. The promiscuous and complex consequences of experience-dependent regulation pose a significant challenge for 


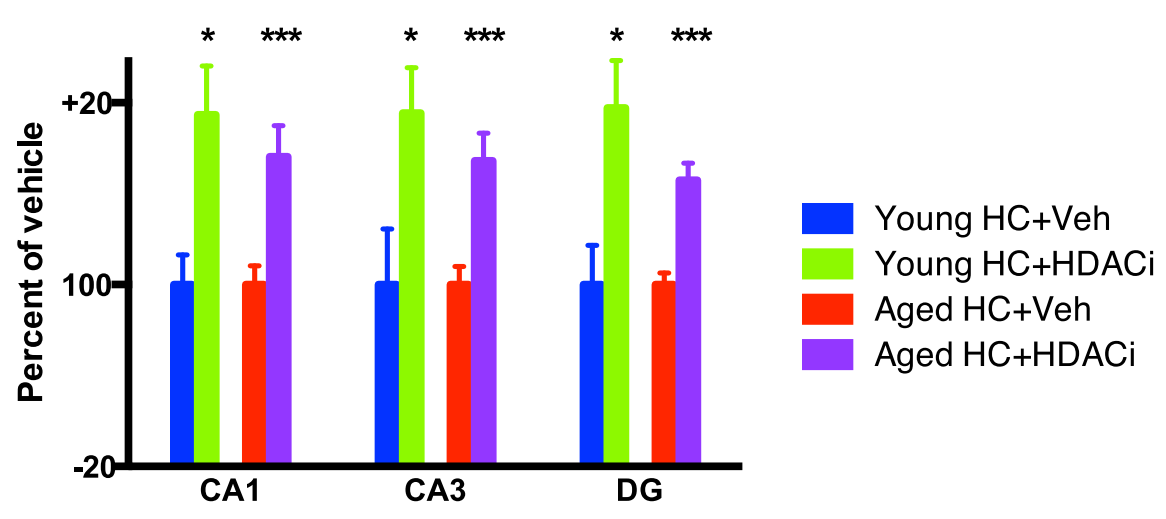

Figure 6. Acute HDACi treatment increases histone $\mathrm{H} 4$ acetylation in the young and aged hippocampus. Quantification of labeling intensity for acetylated histone $\mathrm{H} 4$ immunofluorescence in $\mathrm{CA1}, \mathrm{CA} 3$, and DG after vehicle (Young $\mathrm{HC}+$ Veh, $n=4$; Aged $\mathrm{HC}+$ Veh, $n=11$ ) or EVX administration (Young HC+HDACi, $n=6$; Aged $\mathrm{HC}+\mathrm{HDACi}, n=10$ ) in young and aged rats. Error bars indicate SEM. ${ }^{*} p \leq 0.05$, relative to age-matched vehicle-treated rats. ${ }^{* * *} p \leq 0.001$, relative to age-matched vehicle-treated rats.

the development of HDACi-based therapeutic interventions for neurocognitive disorders.

The overall pattern of results was similar throughout the principal cell fields of the hippocampus, with the greatest regulation seen in the experience + HDAC inhibition contrast in all areas. Nonetheless, both the magnitude of effect and the specific genes involved displayed substantial regional differences. A fundamental feature of hippocampal organization (Zhao et al., 2001; Datson et al., 2004; Lein et al., 2004), our findings suggest that cell field specificity in gene expression importantly conditions the influence of recent experience on the transcriptional response to elevated histone acetylation. Adopting a similar experimental strategy, we also tested the significance of this interaction for synaptic protein expression in the hippocampus in a rat model of cognitive aging. HDACi administration alone had no detectable effect, as might have been predicted from the mRNA results, and increased immunolabeling for synaptic markers in the young hippocampus was observed only when water maze training was combined with HDAC inhibition. Aged rats with documented deficits in spatial memory, by comparison, failed to display a synaptic protein response to HDACi administration under any condition tested. These findings suggest that the synergistic interaction of recent cognitive experience with elevated histone acetylation levels extends to connectional plasticity and that the capacity for this regulation is blunted in the aged hippocampus.

Although there is considerable evidence that HDACi administration enhances synaptic plasticity and long-term memory (Alarcón et al., 2004; Korzus et al., 2004; Levenson et al., 2004; Fischer et al., 2007; Vecsey et al., 2007; Miller et al., 2008; Guan et al., 2009; Stefanko et al., 2009; Kilgore et al., 2010; Peleg et al., 2010; Hawk et al., 2011), how ongoing experience interacts with elevated histone acetylation levels to influence gene expression has not been entirely clear. One idea is that histone acetylation serves as a molecular tag for recruiting other factors with regulatory activity (Jenuwein and Allis, 2001; Zeng and Zhou, 2002; Mujtaba et al., 2007). Histone acetylation is also thought to influence transcription through remodeling chromatin structure, increasing accessibility by relaxing DNA interactions with histone proteins (Norton et al., 1989; Grunstein, 1997). Although both mechanisms are likely to play a role, our findings indicate that HDACi administration alone has relatively little effect on hippocampal gene and synaptic protein expression. A similarly modest impact on gene expression has been reported previously
(Lopez-Atalaya et al., 2013), suggesting that the more robust response seen following behavioral training is mediated by a permissive mechanism, under the control of experience-dependent cell signaling. In this way, environmental influences are positioned to interact with histone acetylation dynamics and regulate unique gene-specific transcription. The novel insight from the current findings is that this interaction is synergistic such that the molecular response to ongoing experience is qualitatively modified, rather than simply enhanced, by elevated histone acetylation levels. Studies taking advantage of next generation sequencing will be an important step toward defining the mechanisms that mediate the modulatory influence of experience. High-depth surveys interrogating chromatin organization, and nucleosome occupancy and positioning, for example, are now becoming feasible, and data analytic pipelines in development will ultimately enable uniquely comprehensive accounts of how experience regulates the molecular response to $\mathrm{HDACi}$ administration.

Microarray analysis revealed that 3681 unique genes were differentially regulated throughout the hippocampus across all contrasts between experimental conditions. Related research examining gene expression in the context of behavioral testing has focused predominantly on the induction of plasticity-related markers, emphasizing the transcriptionally permissive influence of HDACi treatment and increases in expression (Gräff et al., 2014). It is noteworthy in this context that, among the differentially expressed genes we observed in the experience + HDAC inhibition contrast in CA1 (Fig. 3), 43\% were downregulated. Indeed, in the HDAC inhibition alone comparison, downregulation predominated (65\% vs 35\% down- and up-related, respectively). In addition, whereas a subset of genes revealed by the experience + HDAC inhibition contrast has been directly implicated in memory-related plasticity, the overall scope of regulation was much broader, including genes involved in lipid metabolism, cell cycle and reproductive system function, and neurological and cardiovascular disease, among others (a full list of regulated gene networks, canonical pathways and molecules will be available in GEO). The diversity of cell biological functions impacted by HDACi treatment (Bolden et al., 2006), together with the powerful modulatory influence of ongoing experience revealed here, serves as an important cautionary note for the development of therapeutics targeting neuroepigenetics.

Recent evidence suggests that disrupted epigenetic regulation contributes to age-related deficits in synaptic plasticity and memory (Peleg et al., 2010; Penner et al., 2010, 2011; Castellano et al., 2012). Informed by the outcome of the microarray analysis, we used a parallel design to directly test the influence of behavioral training on the synaptic protein response to HDACi treatment in young rats and aged animals with spatial memory impairment, measured by immunofluorescence labeling for presynaptic, intrajunctional, and postsynaptic markers in the hippocampus. Acute HDACi administration alone had no detectable effect on synaptic protein expression in either young or aged subjects, consistent with the limited regulation observed at the gene expression level under this condition. In the young hippocampus, however, a robust increase was observed for multiple synaptic 
A
Young
$\mathrm{HC}+\mathrm{HDACi}$

\section{Young \\ RPC+HDACi}
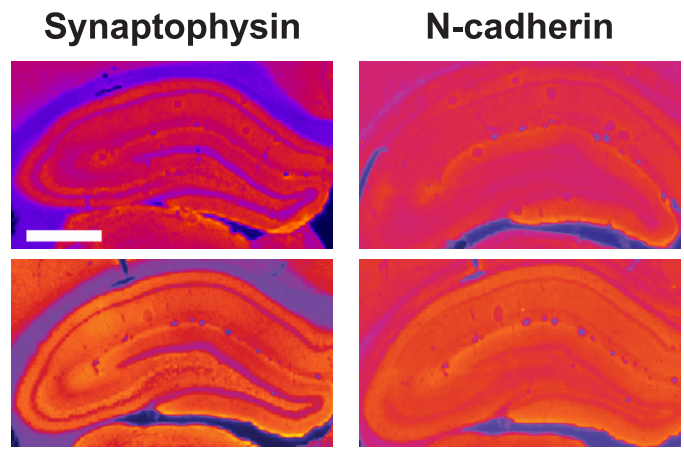

2314

45854

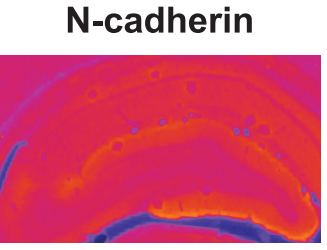

\section{Spinophilin}
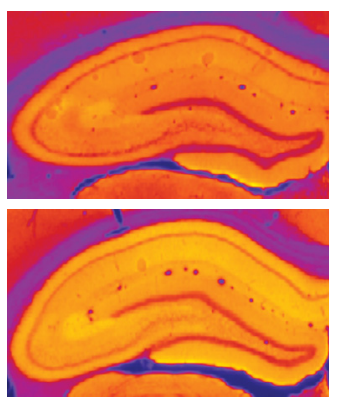

B

Young
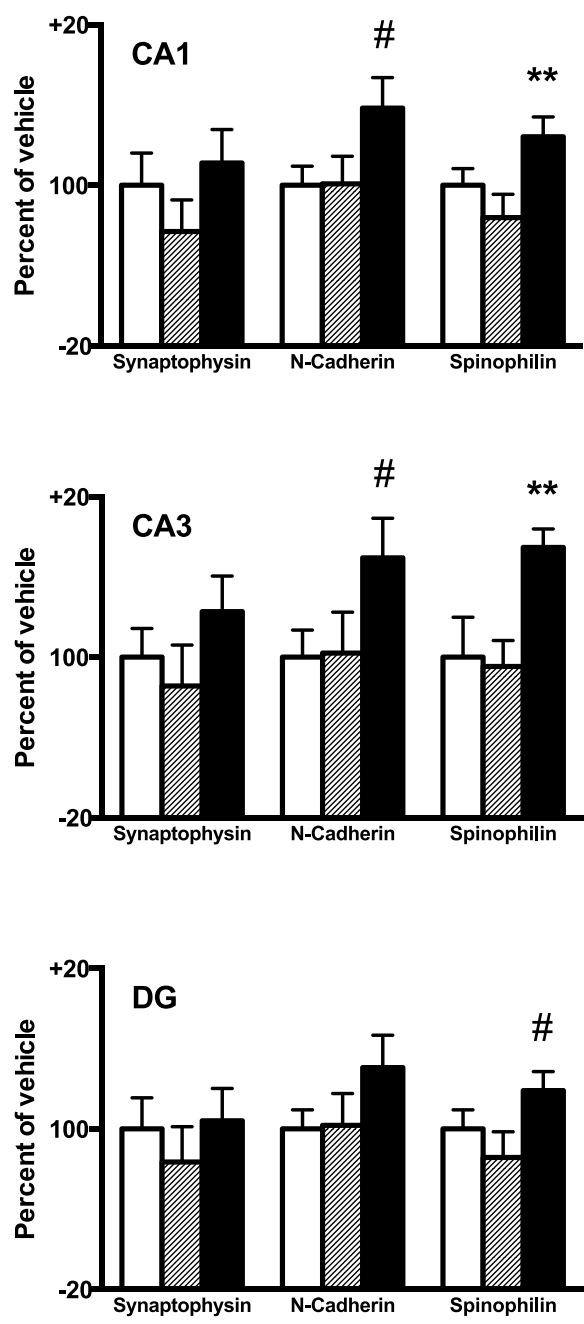

Aged
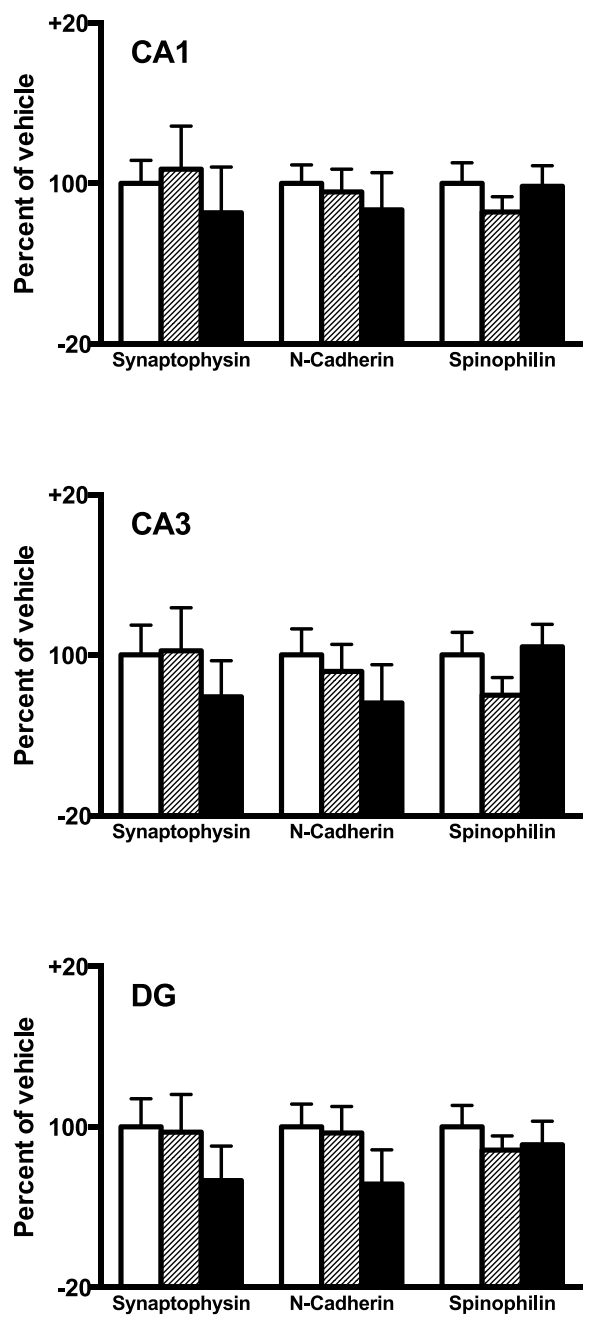

DC+Veh שב HC+HDACi

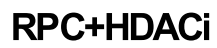

Figure 7. HDACi administration combined with water maze training enhances synaptic marker expression in the young adult, but not aged, hippocampus. $A$, Representative pseudo-colored images of synaptophysin, N-cadherin, and spinophilin immunofluorescence in Young HC+HDACi and Young RPC + HDACi groups. Calibration: 1 mm. B, Associated quantification of immunofluorescence intensity in the principal connectional zones of the hippocampus in vehicle (Young $\mathrm{HC}+$ Veh, $n=6$; Aged HC + Veh, $n=11)$, HDACi (Young HC + HDACi, $n=5 ;$ Aged HC + HDACi, $n=$ 11 ), and HDACi plus RPC-treated young and aged rats (Young RPC $+\mathrm{HDACi}, n=8 ;$ Aged RPC $+\mathrm{HDACi}, n=7$ ). All quantification was performed on the original, unmodified grayscale images. Error bars indicate SEM. ${ }^{\#} p \leq 0.10$, relative to Young $H C+$ HDACi rats. ${ }^{* *} p \leq 0.01$, relative to Young $H C+$ HDACi rats. 
markers in all connectional zones when rats received behavioral training in conjunction with HDACi treatment. These findings suggest that the enhanced labeling for synaptic markers and increased dendritic spine number reported in previous studies with HDACi may critically reflect the background of environmental enrichment and behavioral training included in those experiments (Fischer et al., 2007; Guan et al., 2009; Gräff et al., 2014). Together, the available evidence is consistent with the possibility that the synergistic interaction of experience-dependent signaling with elevated histone acetylation is sufficient to promote significant circuit remodeling in the young adult hippocampus. Quantitative electron microscopic analysis is needed to confirm this proposal and to define in detail the influence of experience on the synaptic morphological response to HDACi administration.

In contrast to the findings for young subjects, we failed to detect any experimental treatment effect on synaptic protein expression in the aged hippocampus. We directly confirmed our earlier observation that EVX administration significantly increases histone acetylation in the aged rat hippocampus (Castellano et al., 2014), discounting the possibility that the lack of effect on synaptic protein expression is attributable to a loss of target efficacy in aging. A plausible alternative is that aged rats with memory impairment fail to engage the critical experiencedependent signaling that mediates the downstream influence of behavioral training. Indeed, previous research has documented disrupted signaling involving multiple pathways in association with cognitive aging (Nicolle et al., 1999; Ramos et al., 2003; Foster, 2007; Dagnas et al., 2013), and that might thereby contribute to the lack of a synaptic protein response to combined water maze training and HDACi treatment. Studies taking advantage of animal models that display greater individual variability in cognitive outcome (Gallagher et al., 1993; Haberman et al., 2011; Morrison and Baxter, 2012), including aged subjects with intact capacities, will be valuable for testing this proposal and for linking the results more specifically to the status of memory. Growing evidence indicates that epigenetic regulation is also directly affected in aging (Peleg et al., 2010; Penner et al., 2010, 2011; Castellano et al., 2012; Dagnas et al., 2013), with earlier findings from our group suggesting that coordinated epigenetic control in the hippocampus is broadly disrupted selectively in aged rats with memory impairment (Castellano et al., 2012). Disentangling the effects of aging on epigenetic regulation from the role of changes in upstream signaling is an important challenge for investigation, with significant implications for therapeutic development. The intriguing prediction from the findings presented here is that the response to intervention targeting neuroepigenetic control may vary widely in association with an individual's unique history and ongoing experience. Harnessing the power of these dynamics provides a potentially powerful path toward personalized treatment for cognitive disorders of aging and neurodegenerative disease.

\section{References}

Abel T, Zukin RS (2008) Epigenetic targets of HDAC inhibition in neurodegenerative and psychiatric disorders. Curr Opin Pharmacol 8:57-64. CrossRef Medline

Alarcón JM, Malleret G, Touzani K, Vronskaya S, Ishii S, Kandel ER, Barco A (2004) Chromatin acetylation, memory, and LTP are impaired in $\mathrm{CBP}^{+1-}$ mice: a model for the cognitive deficit in Rubinstein-Taybi syndrome and its amelioration. Neuron 42:947-959. CrossRef Medline

Alberini CM (2009) Transcription factors in long-term memory and synaptic plasticity. Physiol Rev 89:121-145. CrossRef Medline

Allen PB, Ouimet CC, Greengard P (1997) Spinophilin, a novel protein phosphatase 1 binding protein localized to dendritic spines. Proc Natl Acad Sci U S A 94:9956-9961. CrossRef Medline
Bailey CH, Kandel ER (1993) Structural changes accompanying memory storage. Annu Rev Physiol 55:397-426. CrossRef Medline

Bannerman DM, Sprengel R, Sanderson DJ, McHugh SB, Rawlins JN, Monyer H, Seeburg PH (2014) Hippocampal synaptic plasticity, spatial memory and anxiety. Nat Rev Neurosci 15:181-192. CrossRef Medline

Bolden JE, Peart MJ, Johnstone RW (2006) Anticancer activities of histone deacetylase inhibitors. Nat Rev Drug Discov 5:769-784. CrossRef Medline

Castellano JF, Fletcher BR, Kelley-Bell B, Kim DH, Gallagher M, Rapp PR (2012) Age-related memory impairment is associated with disrupted multivariate epigenetic coordination in the hippocampus. PLoS One 7:e33249. CrossRef Medline

Castellano JF, Fletcher BR, Patzke H, Long JM, Sewal A, Kim DH, Kelley-Bell B, Rapp PR (2014) Reassessing the effects of histone deacetylase inhibitors on hippocampal memory and cognitive aging. Hippocampus 24: 1006-1016. CrossRef Medline

Cheadle C, Vawter MP, Freed WJ, Becker KG (2003) Analysis of microarray data using Z score transformation. J Mol Diagn 5:73-81. CrossRef Medline

Dagnas M, Guillou JL, Prévôt T, Mons N (2013) HDAC inhibition facilitates the switch between memory systems in young but not aged mice. J Neurosci 33:1954-1963. CrossRef Medline

Datson NA, Meijer L, Steenbergen PJ, Morsink MC, van der Laan S, Meijer OC, de Kloet ER (2004) Expression profiling in laser-microdissected hippocampal subregions in rat brain reveals large subregion-specific differences in expression. Eur J Neurosci 20:2541-2554. CrossRef Medline

Dokmanovic M, Clarke C, Marks PA (2007) Histone deacetylase inhibitors: overview and perspectives. Mol Cancer Res 5:981-989. CrossRef Medline

Fischer A, Sananbenesi F, Wang X, Dobbin M, Tsai LH (2007) Recovery of learning and memory is associated with chromatin remodelling. Nature 447:178-182. CrossRef Medline

Fletcher BR, Calhoun ME, Rapp PR, Shapiro ML (2006) Fornix lesions decouple the induction of hippocampal arc transcription from behavior but not plasticity. J Neurosci 26:1507-1515. CrossRef Medline

Fletcher BR, Hill GS, Long JM, Gallagher M, Shapiro ML, Rapp PR (2014) A fine balance: regulation of hippocampal Arc/Arg3.1 transcription, translation and degradation in a rat model of normal cognitive aging. Neurobiol Learn Mem 115:58-67. CrossRef Medline

Foster TC (2007) Calcium homeostasis and modulation of synaptic plasticity in the aged brain. Aging Cell 6:319-325. CrossRef Medline

Fujita Y, Morinobu S, Takei S, Fuchikami M, Matsumoto T, Yamamoto S, Yamawaki S (2012) Vorinostat, a histone deacetylase inhibitor, facilitates fear extinction and enhances expression of the hippocampal NR2Bcontaining NMDA receptor gene. J Psychiatr Res 46:635-643. CrossRef Medline

Gallagher M, Burwell R, Burchinal M (1993) Severity of spatial learning impairment in aging: development of a learning index for performance in the Morris water maze. Behav Neurosci 107:618-626. CrossRef Medline

Gottschall PE, Ajmo JM, Eakin AK, Howell MD, Mehta H, Bailey LA (2010) Panel of synaptic protein ELISAs for evaluating neurological phenotype. Exp Brain Res 201:885-893. CrossRef Medline

Gräff J, Kim D, Dobbin MM, Tsai LH (2011) Epigenetic regulation of gene expression in physiological and pathological brain processes. Physiol Rev 91:603-649. CrossRef Medline

Gräff J, Joseph NF, Horn ME, Samiei A, Meng J, Seo J, Rei D, Bero AW, Phan TX, Wagner F, Holson E, Xu J, Sun J, Neve RL, Mach RH, Haggarty SJ, Tsai LH (2014) Epigenetic priming of memory updating during reconsolidation to attenuate remote fear memories. Cell 156:261-276. CrossRef Medline

Grunstein M (1997) Histone acetylation in chromatin structure and transcription. Nature 389:349-352. CrossRef Medline

Guan JS, Haggarty SJ, Giacometti E, Dannenberg JH, Joseph N, Gao J, Nieland TJ, Zhou Y, Wang X, Mazitschek R, Bradner JE, DePinho RA, Jaenisch R, Tsai LH (2009) HDAC2 negatively regulates memory formation and synaptic plasticity. Nature 459:55-60. CrossRef Medline

Guzowski JF, Lyford GL, Stevenson GD, Houston FP, McGaugh JL, Worley PF, Barnes CA (2000) Inhibition of activity-dependent arc protein expression in the rat hippocampus impairs the maintenance of long-term potentiation and the consolidation of long-term memory. J Neurosci 20:3993-4001. Medline

Haberman RP, Colantuoni C, Stocker AM, Schmidt AC, Pedersen JT, Gallagher M (2011) Prominent hippocampal CA3 gene expression profile 
in neurocognitive aging. Neurobiol Aging 32:1678-1692. CrossRef Medline

Hawk JD, Abel T (2011) The role of NR4A transcription factors in memory formation. Brain Res Bull 85:21-29. CrossRef Medline

Hawk JD, Florian C, Abel T (2011) Post-training intrahippocampal inhibition of class I histone deacetylases enhances long-term object-location memory. Learn Mem 18:367-370. CrossRef Medline

Jenuwein T, Allis CD (2001) Translating the histone code. Science 293: 1074-1080. CrossRef Medline

Kandel ER (2012) The molecular biology of memory: cAMP, PKA, CRE, CREB-1, CREB-2, and CPEB. Mol Brain 5:14. CrossRef Medline

Kandel ER, Dudai Y, Mayford MR (2014) The molecular and systems biology of memory. Cell 157:163-186. CrossRef Medline

Kilgore M, Miller CA, Fass DM, Hennig KM, Haggarty SJ, Sweatt JD, Rumbaugh G (2010) Inhibitors of class 1 histone deacetylases reverse contextual memory deficits in a mouse model of Alzheimer's disease. Neuropsychopharmacology 35:870-880. CrossRef Medline

Korzus E, Rosenfeld MG, Mayford M (2004) CBP histone acetyltransferase activity is a critical component of memory consolidation. Neuron 42:961972. CrossRef Medline

Lattal KM, Barrett RM, Wood MA (2007) Systemic or intrahippocampal delivery of histone deacetylase inhibitors facilitates fear extinction. Behav Neurosci 121:1125-1131. CrossRef Medline

Lein ES, Zhao X, Gage FH (2004) Defining a molecular atlas of the hippocampus using DNA microarrays and high-throughput in situ hybridization. J Neurosci 24:3879-3889. CrossRef Medline

Levenson JM, O’Riordan KJ, Brown KD, Trinh MA, Molfese DL, Sweatt JD (2004) Regulation of histone acetylation during memory formation in the hippocampus. J Biol Chem 279:40545-40559. CrossRef Medline

Lopez-Atalaya JP, Ito S, Valor LM, Benito E, Barco A (2013) Genomic targets, and histone acetylation and gene expression profiling of neural HDAC inhibition. Nucleic Acids Res 41:8072-8084. CrossRef Medline

Miller CA, Campbell SL, Sweatt JD (2008) DNA methylation and histone acetylation work in concert to regulate memory formation and synaptic plasticity. Neurobiol Learn Mem 89:599-603. CrossRef Medline

Morrison JH, Baxter MG (2012) The ageing cortical synapse: hallmarks and implications for cognitive decline. Nat Rev Neurosci 13:240-250. Medline

Moser MB (1999) Making more synapses: a way to store information? Cell Mol Life Sci 55:593-600. CrossRef Medline

Mujtaba S, Zeng L, Zhou MM (2007) Structure and acetyl-lysine recognition of the bromodomain. Oncogene 26:5521-5527. CrossRef Medline

Nicolle MM, Colombo PJ, Gallagher M, McKinney M (1999) Metabotropic glutamate receptor-mediated hippocampal phosphoinositide turnover is blunted in spatial learning-impaired aged rats. J Neurosci 19:9604-9610. Medline
Norton VG, Imai BS, Yau P, Bradbury EM (1989) Histone acetylation reduces nucleosome core particle linking number change. Cell 57:449-457. CrossRef Medline

Peixoto L, Abel T (2013) The role of histone acetylation in memory formation and cognitive impairments. Neuropsychopharmacology 38:62-76. CrossRef Medline

Peleg S, Sananbenesi F, Zovoilis A, Burkhardt S, Bahari-Javan S, Agis-Balboa RC, Cota P, Wittnam JL, Gogol-Doering A, Opitz L, Salinas-Riester G, Dettenhofer M, Kang H, Farinelli L, Chen W, Fischer A (2010) Altered histone acetylation is associated with age-dependent memory impairment in mice. Science 328:753-756. CrossRef Medline

Penner MR, Roth TL, Barnes CA, Sweatt JD (2010) An epigenetic hypothesis of aging-related cognitive dysfunction. Front Aging Neurosci 2:9. CrossRef Medline

Penner MR, Roth TL, Chawla MK, Hoang LT, Roth ED, Lubin FD, Sweatt JD, Worley PF, Barnes CA (2011) Age-related changes in Arc transcription and DNA methylation within the hippocampus. Neurobiol Aging 32: 2198-2210. CrossRef Medline

Ramos BP, Birnbaum SG, Lindenmayer I, Newton SS, Duman RS, Arnsten AF (2003) Dysregulation of protein kinase a signaling in the aged prefrontal cortex: new strategy for treating age-related cognitive decline. Neuron 40:835-845. CrossRef Medline

Rusakov DA, Davies HA, Harrison E, Diana G, Richter-Levin G, Bliss TV, Stewart MG (1997) Ultrastructural synaptic correlates of spatial learning in rat hippocampus. Neuroscience 80:69-77. CrossRef Medline

Shanley TP, Cvijanovich N, Lin R, Allen GL, Thomas NJ, Doctor A, Kalyanaraman M, Tofil NM, Penfil S, Monaco M, Odoms K, Barnes M, Sakthivel B, Aronow BJ, Wong HR (2007) Genome-level longitudinal expression of signaling pathways and gene networks in pediatric septic shock. Mol Med 13:495-508. CrossRef Medline

Stefanko DP, Barrett RM, Ly AR, Reolon GK, Wood MA (2009) Modulation of long-term memory for object recognition via HDAC inhibition. Proc Natl Acad Sci U S A 106:9447-9452. CrossRef Medline

Tusher VG, Tibshirani R, Chu G (2001) Significance analysis of microarrays applied to the ionizing radiation response. Proc Natl Acad Sci U S A 98: 5116-5121. CrossRef Medline

Vecsey CG, Hawk JD, Lattal KM, Stein JM, Fabian SA, Attner MA, Cabrera SM, McDonough CB, Brindle PK, Abel T, Wood MA (2007) Histone deacetylase inhibitors enhance memory and synaptic plasticity via CREB: CBP-dependent transcriptional activation. J Neurosci 27:6128-6140. CrossRef Medline

Zeng L, Zhou MM (2002) Bromodomain: an acetyl-lysine binding domain. FEBS Lett 513:124-128. CrossRef Medline

Zhao X, Lein ES, He A, Smith SC, Aston C, Gage FH (2001) Transcriptional profiling reveals strict boundaries between hippocampal subregions. J Comp Neurol 441:187-196. CrossRef Medline 